\title{
Multiple wh-quantifier float in dialectal English
}

\author{
Sarah Asinari *
}

\begin{abstract}
This paper focuses on a dialect of English called Philadelphian Irish English (PhIrE) which allows quantifier float under wh-movement. This dialect also allows multiple quantifiers to be stranded at various stages of intermediate movement, a novel pattern not observed before. Here I focus on the patterns of multiple quantifier float and their restrictions. I propose that single and multiple quantifier float are derived through two different mechanisms: stranding and copying, respectively. Single quantifier float is derived through the standard stranding mechanisms, while wh-phrases in multiple quantifier constructions leave multiple copies which then undergo scattered deletion (See Bošković 2001; Nunes 2004).
\end{abstract}

Keywords. quantifier float; dialectal English; multiple quantifiers; successive-cyclic movement

1. Introduction. This paper focuses on a dialect of English native to the Irish boroughs of Northeast Philadelphia - Kensington and Fishtown. Philadelphian Irish English (PhIrE) exhibits quantifier float similar to West Ulster English (WUE) (1) (See McCloskey 2000). These dialects allow for what I will be calling wh-associated quantifiers, illustrated by (1a) and quantifiers which are floated or stranded under wh-movement illustrated by (1b), which is not acceptable in Standard English.

(1) a. What all did you get for Christmas?

(Some Standard English)

b. What did you get all for Christmas?

(WUE \& PhIrE)

The goal of this paper is to discuss quantifier float patterns in PhIrE. For reasons that will become lear later, the paper will follow the approach where quantifiers are floated under movement, marking different steps of intermediate movement (Sportiche 1988; Déprez 1989; Shlonsky 1991; Merchant 1996; McCloskey 2000; Bošković 2004; a.o.).

What is unique to PhIrE is that it allows multiple quantifiers to be floated at different steps of intermediate movement, as shown by (2). In (2), we see various quantifiers

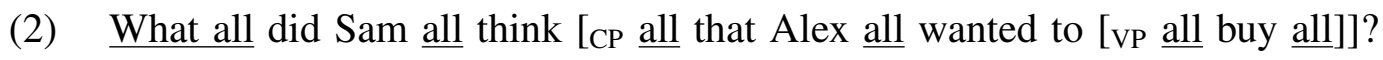

I will closely examine the patterns for multiple quantifier float. The account provided will conclude that multiple quantifiers are not actually floated under standard quantifier stranding movement.

The data in this paper were collected using four speakers from the Philadelphia area, in addition to the author's judgments. All examples are given as a consensus in judgement between speakers, should speakers vary in their judgments, they will be so marked in footnotes.

\footnotetext{
* I would like to thank my grandmother and my other consultants in North Philly for (mostly) backing up my own judgements and for showing me the importance of dialectal variance. I'd also like to thank Zeljko Bošković, Adrian Stegovec, Vicki Carstens, and Coppe van Urk for their comments and advice. Thanks also to Guglielmo Cinque, Kyle Johnson, Jim McCloskey, Jason Merchant, Masha Polinsky, and Gary Thoms for their comments on various aspects of this project. This material is based upon work supported by the program in Science of Learning Art of Communication at the University of Connecticut, which is supported by the National Science Foundation under Grant DGE-1747486. Any opinions, findings, and conclusions or recommendations expressed in this material are those of the author(s) and do not necessarily reflect the views of the National Science Foundation. Author: University of Connecticut (sarah.asinari@uconn.edu)
} 
There is, of course, some variation between judgements in this dialect, as is consistent for WUE, which shows similar variation (cf. McCloskey 2000; Henry 2012). There are also additional prosodic factors at work with quantifiers in this dialect. Most speakers largely disprefer quantifiers in utterance final positions, but these effects are alleviated by adding an adjunct. This is also attested for WUE (McCloskey 2000; Henry 2012). The adverbs are often left out in the example sentences below for expository purposes, however these prosodic considerations have been taken into account extensively while testing. Should the lack of an utterance final adjunct drastically affect the judgments, it will be provided in the example.

In Section 2, I will discuss the patterns for single quantifier float in PhIrE, in order to establish a baseline for quantifier float in this particular variety of English. Section 3 investigates the various conditions under which multiple quantifiers can be floated. Section 4 establishes a difference between quantifier stranding and quantifier copying. Section 5 concludes this paper.

2. Quantifier stranding in PhIrE. Wh-quantifier float in West Ulster English is largely restricted to SpecCP and object shift positions (McCloskey 2000; See also Bošković 2004 for floating in non-theta positions). In PhIrE floating is not limited to SpecCP, however it is, despite being more pervasive, restricted, so it is not available in all the intermediate movement positions. The patterns available in PhIrE fall somewhere in the middle of these two.

In (3), we see different positions for floated quantifiers for objects. In (3a-b), it's not possible to have a wh-associated quantifier after the subject. This SpecvP position is not an available position to float quantifiers.

(3) a. ?*What does Sam [vp all think [CP that Alex [vP wanted to [vp buy]]]]?

b. ?*What does Sam [vP think [CP that Alex [vp all wanted to [vp buy]]]]?

Unsurprisingly, the quantifier can be floated in the embedded SpecCP, as illustrated by (4a). In (4b), quantifiers cannot be floated at the edge of the infinitive; however, they can appear in the middle of the infinitive as shown by (4c). Finally, much like WUE, quantifiers can also be floated in the base position, as illustrated by $(4 \mathrm{~d})$.

(4) a. What does Sam [ve think [CP all that Alex [ve wanted to [ve buy]]]]?

b. *What does Sam [vP think [CP that Alex [vP wanted all to [vP buy]]]]?

c. What does Sam [vP think [CP that Alex [vp wanted to [ve all buy]]]]?

d. What does Sam [vP think [CP that Alex [vP wanted to [vP buy all]]]]?

Subjects behave similarly, as (5) demonstrates that each position that was available for quantifier float with objects is also available for subjects, provided that movement can in principle pass through that position. To illustrate this with a partial paradigm, we see that in (5a) the quantifier cannot be floated after the higher subject. However, there is an available position for quantifier float following the matrix verb (5b).

(5) a. ?*Who does Sam [vp all think [CP/IP wanted to leave Alex?

b. Who does Sam [ve think [CP/IP all wanted to leave Alex?

Quantifier float is also possible under wh-movement out of PPs. Like the subjects and other objects, quantifiers cannot be floated in SpecvP, as shown in (6) for both matrix and em-

\footnotetext{
${ }^{1}$ For the purposes of this section, wh-associated quantifiers like 'what all' are omitted from the examples, however, they are always a grammatical option in PhIrE, as in a variety of Standard English dialects.
} 
bedded subjects.

(6) a. ?*Who did Kamal [vP all say [CP that Aisha [vP needed to [vP speak [pP to]]]]]?

b. ?*Who did Kamal [ve say [CP that Aisha [vP all needed to [vP speak [PP to?

The main focus of the paradigm in (6) is that for movement out of the PP, a quantifier can be floated in the specifier of the PP, as shown by (7d) or in the base position in (7e). While the latter pattern is something attested in WUE, the former is something entirely new to PhIrE and is ungrammatical in WUE. Additionally, quantifiers cannot be floated in the specifier of the infinitive in (7b).

(7) a. Who did Kamal [vP say [CP all that Aisha [vP needed to [vp speak [pP to?

b. *Who did Kamal [vp say [CP that Aisha [vp needed all to [vp speak [Pp to]]]]]?

c. Who did Kamal [vP say [CP that Aisha [vP needed to [vP all speak [PP to]]]]]?

d. Who did Kamal [vP say [CP that Aisha [vP needed to [vp speak [PP all to]]]]?

e. Who did Kamal [vP say [CP that Aisha [vP needed to [vP speak [PP to all]]]]]?

Embedded questions behave similarly to matrix questions for both subjects and objects. Examples (8) illustrate this for subjects: quantifiers still can be floated in all the same positions in (8) as they can in (5). In (8), we see that post-subject quantifier float is disallowed, while floating between the two clauses is permitted.

(8) a. ?*I wonder [CP who Sam [ve all thought [CP/IP wanted to leave Alex]]].

b. I wonder [CP who Sam [ ${ }_{\mathrm{vP}}$ thought [CP/IP all wanted to leave Alex]]].

The patterns also stay consistent for movement out of PPs like in (9). In (9a), we see the more standard wh-associated quantifier, which is available for some dialects of Standard English. Post-verbal subjects are still disallowed in the embedded contexts, as shown in (9b). The specifier of the infinitive is an unavailable position for quantifier float, shown by (9c). However, (9d) shows that there is an available position for quantifier float in SpecVP of the infinitive. For the PP, both the specifier and the object of the preposition can host quantifiers.

(9) a. I wonder [ $\mathrm{CP}$ who all Aisha [ ${ }_{\mathrm{vP}}$ needed to [VP speak [PP to]]]].

b. ?*I wonder [CP who Aisha [vP all needed to [vP speak [PP to]]]].

c. *I wonder [CP who Aisha [vP needed all to [vP speak [PP to]]]].

d. I wonder [CP who Aisha [vP needed to [vP all speak [PP to]]]].

e. I wonder [CP who Aisha [vP needed to [vP speak [PP all to]]]].

f. I wonder [CP who Aisha [vP needed to [vP speak [PP to all]]]].

The single wh-quantifier float patterns show that there are multiple positions for movement, more than just at CP edges. Rather these data show that we're looking at movement patterns that fall somewhere in between just $\mathrm{CP}$ edges and every projection on the way of movement.

3. Multiple quantifier float in PhIrE. Multiple quantifiers are a phenomenon that is entirely unique to Philadelphian Irish English and have a variety of properties. There's largely no restriction on how many floating quantifiers are pronounced. They don't have to appear at every possible floating position. Whether it is two or four quantifiers, it is not necessary to float them in every position in which single float is possible, some such positions can be skipped between multiple floated quantifiers. The following examples will not be exhaustive, but each 
will represent a possible combination. Impossible combinations will be specified.

In (10), the floated quantifiers can appear in various positions. For (10a), quantifiers appear in SpecCP of the intermediate clause and in SpecvP of the most embedded clause. (10b) shows an associated quantifier in the matrix SpecCP, as well as quantifiers after both subjects. Note that this position was ungrammatical for single quantifier float, yet appears with multiple quantifiers. The maximal amount of quantifiers is shown in (10c).

(10) a. What does Sam [vP think [CP all that Alex [vp wanted to [vp all buy]]]]?

b. What all does Sam [vP all think [cP that Alex [vP all wanted to [vP all buy]]]?

c. What all does Sam [vP all think [CP all that Alex [vP all wanted to [vp all buy all]]]]?

Subjects show similar patterns with quantifier float under wh-movement, as shown by (11b). In (11a), there is a wh-associated quantifier in the matrix SpecCP. In (11b), there is additionally a floated quantifier that follows the matrix subject and another one between the two embedded verbs.

(11) a. Who all does Sam [ve all think [CP/IP wanted to leave Alex]]?

b. Who all does Sam [vP all think [CP/IP all wanted to leave Alex]]?

For wh-movement out of PPs, we see similar patterns for multiple quantifiers. In (12a), there is a wh-associated quantifier, followed by quantifiers after both subjects, and then with a quantifier in SpecPP. The highest quantifier in (12b) is in the intermediate SpecCP position, followed by a quantifier in SpecVP and by a quantifier in the base position. (12c) shows every possible quantifier in a multiple quantifier construction for this example.

a. Who all did Kamal [ ${ }_{\mathrm{vP}}$ all say [CP that Aisha [vP all needed to [vP speak [PP all to]]1]]?

b. Who did Kamal say [CP $\underline{\text { all }}$ that Aisha needed to [VP all speak [PP to all]]]?

c. Who all did Kamal $\left[_{\mathrm{vP}}\right.$ all say [CP all that Aisha [ ${ }_{\mathrm{vP}}$ all needed to [vP all speak [PP all to all]]]]? ${ }^{2}$

The main restriction on multiple quantifiers that I will establish here is that there must be a c-commanding quantifier in a SpecCP position to license the other floated quantifiers. The generalization is illustrated by the data in (13). If the higest quantifier is not in a SpecCP position, it is not possible to have multiple floated quantifiers. In (13b), there is no quantifier in either SpecCP position, which results in ungrammatical multiple 'all's. On the other hand, in (13a), the presence of a quantifier in the matrix SpecCP makes it possible to have multiple 'all's.

(13) a. What all does Sam [vP think [ ${ }_{\mathrm{CP}}$ that Alex [vP all wanted to [vP all buy]]]]?

b. *What does Sam [vp think [CP that Alex [vP all wanted to [vp all buy]]]]?

The highest quantifier need not be in the matrix SpecCP, so long as there is an intermediate 'all' in the embedded SpecCP. If there is only a quantifier in the embedded SpecCP, other quantifiers can only appear lower than that quantifier. In (14a), the highest quantifier is in the

\footnotetext{
${ }^{2}$ When this example is given to speakers, the final 'all' is marked for some speakers. Individual speakers might have a phonological restriction on how close the 'all's can be. If there's a copy present in either SpecPP or the object of the PP, the sentence is fine. It's just the presence of both that, for some speakers, is slightly degraded. This paper will not account for individual variation of this kind within the dialect.
} 
intermediate SpecCP position, and is only followed by quantifiers in the embedded clause. Since other multiple quantifiers are lower than the quantifier in a SpecCP position, we get a grammatical output. (14b) lacks a c-commanding quantifier in a SpecCP, and is, therefore, ungrammatical.

(14) a. What does Sam [vp think [CP all that Alex [vP all wanted to [vP all buy]]]?

b. *What does Sam [ve think [CP that Alex [vP all wanted to [vP all buy]]]]?

If there is only a quantifier in the embedded SpecCP and a quantifier in the matrix clause that is not in SpecCP, the sentence is ungrammatical. In (15a), we see all possible quantifiers, which has the highest quantifier in the matrix SpecCP, which licenses the other quantifiers. In (15b), the highest quantifier is in the matrix SpecvP and is followed by quantifiers in the lower clause. Even though this example has a quantifier in a SpecCP position, it is not the highest quantifier, the sentence is ruled out.

(15) a. What all does Sam [vP all think [CP all that Alex [vP all wanted to [vP all buy]]]]?

b. *What does Sam [vP all think [CP all that Alex [vP all wanted to [vP all buy]]]]?

For embedded questions, the restrictions are similar to their matrix counterparts. Multiple quantifiers can only appear so long as there is a quantifier in a c-commanding SpecCP. In (16a), there is a quantifier in the embedded SpecCP, licensing the lower quantifiers; similarly for (16b) the quantifier in the embedded interrogative SpecCP serves the same function. Things go wrong in (16c), where there is only a quantifier in the most embedded finite clause. However, for the quantifier that follows Sam, there is no quantifier in SpecCP that c-commands it, resulting in a violation, much like the matrix examples.

(16) a. I wonder [ $\mathrm{CP}$ what you think [ $\mathrm{CP}$ all that Sam believes [CP that Alex wanted to [vP all buy]]]].

b. I wonder $\left[_{\mathrm{CP}}\right.$ what all you think $\left[_{\mathrm{CP}}\right.$ that Sam believes $\left[_{\mathrm{CP}}\right.$ that Alex $\left[_{\mathrm{vP}}\right.$ all wanted to [vp all buy]]]]].

c. *I wonder [ ${ }_{\mathrm{CP}}$ what you think [ ${ }_{\mathrm{CP}}$ that Sam [vP all believes [ $\mathrm{CP}$ all that Alex wanted to buy]]]].

4. Stranding vs. copying. In this section, I will argue that single quantifier float and multiple quantifier float in PhIrE are actually derived with two separate mechanisms, namely, stranding and copying. Single quantifiers are floated with the standard method of quantifier float (Sportiche 1988; Déprez 1989; Shlonsky 1991; Doetjes 1997; McCloskey 2000; Bošković 2004; a.o). On the other hand, the derivation for multiple quantifiers involves the regular copying under movement operation, which, occurs with scattered deletion in different parts of the chain in this case (cf. Bošković 2001; Nunes 2004).

4.1. Stranding. The mechanisms behind wh-quantifier float in PhIrE is the same as in quantifier float in Standard English. Following some of the previous literature, the quantifier is merged to the left of the nominal, which then undergoes movement to SpecDP and continues out of the DP (17)(the exact details of the structure are not actually important for our purposes, for another approach see Bošković (2004)). 
(17)

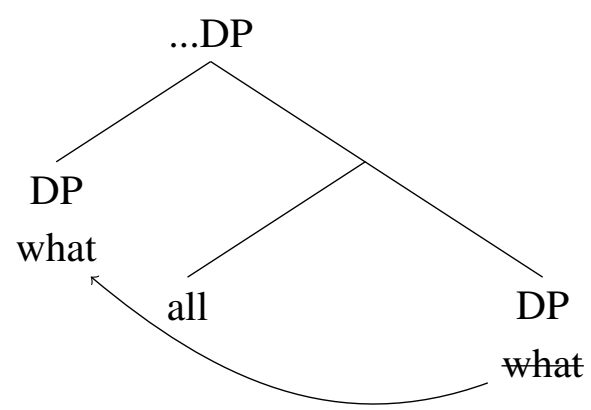

This mechanism is what is behind standard single quantifier float in both Standard English and PhIrE.

4.2. Copying. In order to explain multiple quantifiers, a few mechanisms must be at play: copying, scattered deletion, and finally, stranding. Quantifier copying and scattered deletion rely on the Copy Theory of Movement (Chomsky 1993), which states that phrases undergoing movement leave behind copies, in lieu of traces. In quantifier copying, the complex DP 'all what' is what undergoes movement. Once in a SpecCP, the wh-phrase can undergo typical stranding, leaving the quantifier in the SpecCP and continuing without a quantifier. All copies of 'what' are deleted except for the head of the chain in PF. It is possible to fail to delete more than one copy of 'all', resulting in the appearance of quantifier float.

Thus, in (18a), the complex DP 'all what' undergoes movement, resulting in a chain of copies of 'all what', as shown in (18a). After reaching the final landing site of the matrix SpecCP, the wh-word undergoes movement to SpecDP, resulting in 'what all what', as shown in (18b). At PF, deletion occurs and deletes all but the highest 'what'. Deletion then applies to some but not all of the copies of 'all' resulting in multiple 'all's. This is shown in (18c).

a. all what does Sam all what think all what that Alex all what wanted to all what buy all what?

b. What all what does Sam all what think all what that Alex all what wanted to all what buy all what?

c. What all what does Sam all what think all what that Alex all what wanted to all what buy all what?

d. What all does Sam think all that Alex all wanted to all buy?

When the highest copy of 'all' is in the intermediate SpecCP, the derivation proceeds similarly. Consider example (14), the DP 'all what' undergoes movement to the intermediate SpecCP (19a). At this specifier, the wh-phrase strands the quantifier (19b), and continues to undergo movement alone (19c). At PF all copies of 'what' except the highest copy are deleted, and deletion applies to some copies of all (19d).

(19) a. PRES Sam think all what that Alex all what wanted to all what buy all what?

b. PRES Sam think what all what that Alex all what wanted to all what buy all what?

c. What does Sam what all what think all what that Alex all what wanted to all what buy all what?

d. What does Sam what think all what that Alex all what wanted to all what buy all what? 
e. What does Sam think all that Alex all wanted to all buy?

Under the above analysis, different mechanisms are involved in single and multiple quantifier float. To show that we are indeed dealing with two separate mechanisms, we will look at the single float examples (3), repeated here as (20). In these examples, it was marked to float a quantifier in SpecvP. However, if we look at the multiple quantifier examples, like (10) repeated here as (21), we see that these positions can host a quantifier.

(20) a. ?*What does Sam all think that Alex wanted to buy?

b. ?*What does Sam think that Alex all wanted to buy?

(21) a. What does Sam think all that Alex wanted to all buy?

b. What all does Sam all think that Alex all wanted to all buy?

c. What all does Sam all think all that Alex all wanted to all buy all?

I suggest that this difference is there because quantifiers cannot actually be stranded under usual quantifier stranding movement in SpecvP. When it comes to intermediate A'-positions, such stranding movement can only strand quantifiers in a SpecCP position. This was in fact also observed for WUE, where quantifiers also cannot be stranded in SpecvP (McCloskey 2000; ex. 15). What these multiple quantifier contexts show us is that there is movement through this position, but it is not an available position for stranding.

In (22), we see the ungrammatical derivation of stranding a quantifier in SpecvP. In (22), after movement to the higher SpecvP position, the quantifier is stranded under regular stranding movement, which is not possible.

(22) a. PRES Sam think that Alex wanted to buy all what?

b. PRES Sam think that Alex wanted to all what buy all what?

c. PRES Sam think that Alex *what all what wanted to all what buy all what?

d. What does Sam what think what that Alex what all what wanted to all what buy all what?

e. *What does Sam what think what that Alex what all what wanted to all what buy all what?

5. Conclusion. This paper has presented quantifier float data from Philadelphian Irish English, which exhibits a unique wh-quantifier pattern - multiple wh-quantifiers. I have presented evidence that the two phenomena present in PhIrE, multiple and single quantifier float, come about through two separate mechanisms. Single quantifier float is derived through quantifier stranding, the same kind of operation that is responsible for quantifier float in standard English. Multiple quantifier float is derived through movement of the DP 'all what', the appearance of multiple floated quantifiers arises because more than one copy of 'all' can fail to be deleted.

\section{References}

Bošković, Željko. 2001. On the nature of the syntax-phonology interface: Cliticization and related phenomena. Leiden: Brill.

Bošković, Željko. 2004. Be careful where you float your quantifiers. Natural Language \& Linguistic Theory 22(4). 681-742. https://doi.org/10.1007/s11049-004-2541-z. 
Chomsky, Noam. 1993. A minimalist program for linguistic theory. Cambridge, MA: MIT press. Doetjes, Jenny Sandra. 1997. Quantifiers and selection. Leiden: Leiden University dissertation. Déprez, Viviane Marie. 1989. On the typology of syntactic positions and the nature of chains: Move [alpha] to the specifier of functional projections. Cambridge, MA: MIT dissertation.

Henry, Alison. 2012. Phase edges, quantifier float and the nature of (micro-)variation. Iberia: An International Journal of Theoretical Linguistics 4(2). 23-39.

McCloskey, James. 2000. Quantifier float and wh-movement in an Irish English. Linguistic Inquiry 31(1). 57-84. https://doi.org/10.1162/002438900554299.

Merchant, Jason. 1996. Object scrambling and quantifier float in German. Proceedings of North East Linguistic Society (NELS) 26. 179-194.

Nunes, Jairo. 2004. Linearization of chains and sideward movement. Cambridge, MA: MIT Press.

Shlonsky, Ur. 1991. Quantifiers as functional heads: A study of quantifier float in Hebrew. Lingua 84(2-3). 159-180. https://doi.org/10.1016/0024-3841(91)90069-H.

Sportiche, Dominique. 1988. A theory of floating quantifiers and its corollaries for constituent structure. Linguistic Inquiry 19(3). 425-449. https://www.jstor.org/stable/25164903. 